\title{
Factor V Deficiency
}

\author{
Rosanna Asselta, Ph.D., ${ }^{1}$ and Flora Peyvandi, M.D., Ph.D. ${ }^{2}$
}

\section{ABSTRACT}

Congenital factor $\mathrm{V}(\mathrm{FV})$ deficiency is a bleeding disorder associated with mild to severe hemorrhagic symptoms and a prevalence in the general population of 1 in $1,000,000$ in the homozygous form. Patients with FV deficiency and clinically significant manifestations (mainly involving mucosal tracts) show very low or unmeasurable plasma FV levels and are usually homozygous or compound heterozygous for mutations located in the FV gene (F5). Heterozygous carriers have approximately half-normal levels of FV and are usually asymptomatic. Replacement therapy for FV-deficient patients can only rely on administration of fresh-frozen plasma because specific FV concentrates are unavailable and $\mathrm{FV}$ is not present in cryoprecipitate or prothrombin complex concentrates. A total of 56 mutations have been published to date as being responsible for severe or moderately severe FV deficiency; more than two thirds of these are null mutations (mainly decreasing FV expression), with the remaining being missense mutations (usually impairing FV secretion). This article will provide a concise description of the FV protein and gene and will review the molecular, clinical, and therapeutic aspects of FV deficiency.

KEYWORDS: Factor $V$, factor $V$ deficiency, mutational spectrum, clinical manifestations, treatment

Coagulation factor $\mathrm{V}(\mathrm{FV})$, also known as proaccelerin or labile factor, is the protein cofactor required by the prothrombinase complex for thrombin generation. ${ }^{1} \mathrm{FV}$ also represents an important modulator in the early phase of blood clot formation, as it contributes to the anticoagulant pathway by downregulating factor VIII (FVIII) activity. ${ }^{1}$ FV was discovered in 1947 by the Norwegian hematologist Paul Owren while studying a woman affected by a hemophilia-like syndrome. ${ }^{2}$ Given the double role of $\mathrm{FV}$ in the coagulation process, deficiencies in $\mathrm{FV}$ activity and/or antigen levels may result in either hemorrhagic or thrombotic tendencies. Here, an overview concerning the bleeding disorder (from laboratory diagnosis to the molecular characterization of FV-deficiency-causing mutations) is reported.

\section{FV DEFICIENCY}

FV deficiency is a rare bleeding disorder with a prevalence of $\sim 1$ per million in the general population. ${ }^{3}$ It is inherited as an autosomal recessive trait (Online Mendelian Inheritance in Man, OMIM + 227400); parental consanguinity is often present, especially in countries (e.g., Muslim countries and southern India) where consanguineous marriages are frequent and where the disorder occurs up to 10 times more frequently than it does in the Western world. ${ }^{4}$
${ }^{1}$ Department of Biology and Genetics for Medical Sciences, University of Milan, Milan, Italy; ${ }^{2} \mathrm{~A}$. Bianchi Bonomi Hemophilia and Thrombosis Center, Department of Medicine and Medical Specialties, IRCCS Maggiore Hospital, Mangiagalli and Regina Elena Foundation, University of Milan and Luigi Villa Foundation, Milan, Italy.

Address for correspondence and reprint requests: Dr. Rosanna Asselta, Ph.D., Department of Biology and Genetics for Medical Sciences, University of Milan, Via Viotti 3/5 - 20133 Milan, Italy (e-mail: rosanna.asselta@unimi.it). Ph.D.

Rare Bleeding Disorders; Guest Editor, Flora Peyvandi, M.D.,

Semin Thromb Hemost 2009;35:382-389. Copyright (C) 2009 by Thieme Medical Publishers, Inc., 333 Seventh Avenue, New York, NY 10001, USA. Tel: +1(212) 584-4662.

DOI 10.1055/s-0029-1225760. ISSN 0094-6176. 
FV deficiency can be classified as (1) type I deficiency, or cross-reacting material negative (CRM-) defect, with concordantly low or unmeasurable antigen and functional levels (quantitative defect); (2) type II deficiency, or CRM+ defect, with normal or mildly reduced antigen level associated with reduced coagulant activity (qualitative defect).

Severe FV deficiency (formerly known as parahemophilia) is characterized by FV levels below 10 to $15 \%$ and represents the phenotypic expression of mutations in the homozygous or compound heterozygous state, whereas mild to moderate FV deficiency, showing FV plasma levels $>20$ to $30 \%$, is usually associated with mutations in the heterozygous state.

\section{CLINICAL MANIFESTATIONS}

More than 200 cases of FV deficiency have been described in the literature, the largest clinical studies to date concerning 35 patients from $\operatorname{Iran}^{4}$ and 37 patients collected in the North American Rare Bleeding Disorder Registry. ${ }^{5}$

The Iranian study was exclusively focused on patients suffering from severe FV deficiency: among them, the first bleeding episodes occurred during the first 6 years of life, although only one patient bled from the umbilical cord. Mucosal tract bleedings can be considered the main clinical features of these patients; epistaxis, menorrhagia, and oral cavity hemorrhages being observed quite frequently ( $60 \%$ frequency for each of these symptoms). Hematomas and hemarthroses occurred in only one quarter of patients, and life-threatening bleeding episodes in the central nervous system and in the gastrointestinal tract were extremely rare. ${ }^{4} \mathrm{~A}$ clear confirmation of this clinical spectrum comes from the American registry, ${ }^{5}$ which also described 19 subjects with moderate FV deficiency. Typically, these patients are difficult to diagnose and often come to medical attention because of a positive family history or of an abnormal preoperative laboratory screen. ${ }^{3,5}$ Those who are symptomatic present with skin and mucous membrane bleeding (62\%), whereas musculoskeletal and genitourinary episodes account for the remainder (19\% each). ${ }^{5}$

\section{LABORATORY ASSAYS}

\section{Phenotype Analysis}

FV deficiency can be initially diagnosed observing a prolongation of both the prothrombin time $(\mathrm{PT})$ and activated partial thromboplastin time (APTT) in association with a normal thrombin time (TT). Both PT and APTT are corrected by mixing the patient plasma with a "normal" plasma pool. Deficiency of FV should be confirmed by a PT-based FV assay. It should be kept in mind that individuals having reduced FV should also be tested for FVIII to exclude the occurrence of combined FV and FVIII deficiency. ${ }^{6}$

\section{Genotype Analysis}

\section{THE FV GENE}

The gene coding for human FV (F5) comprises 25 exons, covers a genomic region of $74.5 \mathrm{~kb}$, and maps to the 1q24.2 chromosomal region (UCSC Genome Browser: http://genome.ucsc.edu/). ${ }^{7}$ F5 is mainly expressed by hepatocytes, and there are indications that FV can be synthesized in vivo in the megakaryocyte/ platelet lineage..$^{8-11}$

Very recently, analysis of the $F 5$ splicing pattern in HepG2 cells and human liver evidenced the occurrence of multiple alternative splicing (AS) events. ${ }^{12}$ In particular, among different unproductive ASs, three major ones were detected: two determining the synthesis of in-frame splicing variants and one producing an outof-frame transcript. The latter was demonstrated to be downregulated by the nonsense-mediated mRNA decay (NMD) pathway, a mechanism that selectively detects and degrades transcripts carrying premature termination codons. ${ }^{13}$ This suggests a possible role of the AS-NMD coupling mechanism in the regulation the F5 gene expression. ${ }^{12,14}$

\section{THE FV PROTEIN}

The 6.9-kb FV cDNA ${ }^{15}$ codes for a $330-\mathrm{kDa}$ mature protein of 2196 amino acids, ${ }^{16}$ preceded by a 28 -residue leader peptide. $\mathrm{FV}$ is characterized by a domain structure (A1-A2-B-A3-C1-C2) similar to that of the highly homologous FVIII, ${ }^{1}$ with which it shares $\sim 40 \%$ sequence identity. The only FV region with no significant sequence similarity to any known protein is the B domain, ${ }^{17}$ which contains two tandem repeats of 17 amino acids and 31 tandem repeats of 9 amino acids. FV has 19 cysteines, 14 of which are involved in disulfide bridges, ${ }^{18,19}$ and is characterized by multiple posttranslational modifications (multiple $\mathrm{N}$-linked glycosylation sites are especially present in the B domain). ${ }^{20}$

To date, only the three-dimensional structure of the $\mathrm{C} 2$ domain of human $\mathrm{FV}$ has been determined by $\mathrm{x}$-ray crystallography; the $\mathrm{C} 2$ domain shows an eightstranded $\beta$-barrel core from which three spikes protrude. These spikes mediate binding of activated FV (FVa) to phospholipid membranes. ${ }^{21}$ The description of the crystal structure of activated protein $\mathrm{C}$-inactivated bovine $\mathrm{FVa}$ allowed the reconstruction of a complete molecular model for $\mathrm{FVa}^{22}$ showing that the two $\mathrm{C}$ domains are aligned "edge-to-edge" to form a platform that lifts the A domains (arranged around a pseudo-threefold axis to form a six-bladed wheel) to an 
appropriate height above the membrane for interaction with their physiologic partners. Very recently, this model was substantially confirmed by (a) the low-resolution human FVa three-dimensional structure obtained by Stoilova-McPhie and colleagues, ${ }^{23}$ which also suggested that the two juxtaposed $\mathrm{C}$ domains are inserted deeper into the lipid bilayer than has been previously thought; (b) the solvent-equilibrated model of human FVa proposed by Lee and Chandrasekaran, ${ }^{24}$ which also indicated a possible significant shift toward planarity in the arrangement of the five $\mathrm{FVa}$ domains.

FV has little or no intrinsic procoagulant activity until it is converted to FVa by thrombin or activated factor $\mathrm{X}(\mathrm{FXa})$ by cleavages at three arginine residues (Arg709, Arg1018, Arg1545). The released FVa, lacking the entire $\mathrm{B}$ domain, is composed of a $105-\mathrm{kDa}$ heavy chain (A1-A2 domains) and a 74- or 71-kDa light chain (A3-C1-C2 domains), held together by a single calcium ion. ${ }^{1,17}$ Upon activation, FVa assembles with $\mathrm{FXa}$ on phospholipid membranes, forming a complex that enhances the rate of prothrombin activation by nearly 300,000 -fold. Downregulation of the procoagulant activity of $\mathrm{FVa}$ is achieved by activated protein $\mathrm{C}-$ mediated proteolysis at Arg506, Arg306, and Arg679 residues. $^{1}$

\section{MUTATIONAL SPECTRUM}

Among rare inherited coagulopathies, FV deficiency is one of the least characterized from the molecular point of view, with only 56 genetic defects hitherto described. ${ }^{12,25-38}$ All mutations are located in F5, and those fully published to date are listed in Fig. 1. A very up-to-date database on FV mutations has been compiled by Dr. Hans L. Vos, including also mutations reported in abstract form. ${ }^{39}$ The last release (September 15,2008 ) is available on request (e-mail: H.L.Vos@lumc.nl).

Concerning severe type I FV deficiency, a total of 48 mutations have been described, only one being recurrent (Tyr1702Cys, repeatedly found in Italian individuals). ${ }^{40}$ This confirms the remarkable allelic heterogeneity of the disease. The 48 identified mutations correspond to 21 small insertion/deletion (44\%), 14 missense mutations (29\%), 7 splicing defects (15\%), and 6 nonsense mutations (12\%).

As for mild type I FV deficiency, besides the recurrent Tyr1702Cys mutation, seven additional genetic defects have been reported to date in heterozygous index patients (this survey does not take into account heterozygous relatives of severe $\mathrm{FV}$-deficient patients). Again, all types of point mutations are represented: three nonsense, two missense, one splicing, and one insertion/ deletion mutation.

A decrease in FV levels, responsible for a mild type I deficiency, has also been associated with two FV variants (Fig. 1): a functional polymorphism (Met2120Thr), which was demonstrated to cause an $\sim 25 \%$ reduction in FV levels, ${ }^{41}$ and the HR2 haplotype (named after the His1299Arg polymorphism). HR2 is a FV allele defined by a group of more than 10 polymorphisms ${ }^{42}$; among them, the dominant contribution of the Asp2194Gly variant was demonstrated by expression experiments in eukaryotic cells. ${ }^{43}$

Although the first to be described, FV-New Brunswick (Ala221Val) is the only genetic defect associated with type II deficiency. ${ }^{44}$ The expression of the recombinant $\mathrm{FV}-\mathrm{Ala} 221 \mathrm{Val}$ demonstrated that the mutation interferes with the stability of mutant $\mathrm{FVa}^{45}$

In summary, mutations causing FV deficiency do not cover the full spectrum of possible genetic lesions, as mutations located in the promoter (or other regulatory regions) as well as large deletions are absent. Moreover, an uneven distribution of mutations is observable: most genetic defects are present in exons from 8 to 25 , but missense mutations are completely absent in the large exon 13, coding for the whole $\mathrm{B}$ domain. This can probably be explained by an increased "tolerance" of this domain to variations, as suggested by the fact that it is highly polymorphic and not evolutionarily conserved.

\section{PATHOGENIC MECHANISMS}

Given that mutant FV molecules are present in the bloodstream of the patients at very low levels, the demonstration of the pathogenic role of missense mutations in $\mathrm{F} 5$ has relied on expression studies in mammalian cell lines.

This approach was extremely useful in defining a common denominator for missense mutations: expressed $\mathrm{FV}$ mutant proteins have been in most cases associated with both a secretion impairment and intracellular degradation, probably because of their impaired folding and/or conformational changes leading to retention by the quality control system of the secretory pathway. $25,33,35,36$

With respect to splicing defects, FV platelet and peripheral blood mononuclear cell expression was exploited to provide easy access to mature $F 5$ mRNA. When suitable specimens from $\mathrm{FV}$-deficient patients were unavailable to perform studies at the RNA level, expression of appropriate minigene constructs in eukaryotic cells proved to be an effective tool to unravel the consequences of splicing mutations. In the majority of cases, splicing defects were demonstrated to cause the disruption of a preexisting splice site resulting in exon skipping, whereas the opposite situation (i.e., the activation of a cryptic splice site) appeared a less frequent event. $^{12,25}$

Finally, mutations introducing premature termination codons have been investigated in some cases at the mRNA level, invariantly showing selective degradation of the corresponding transcript by the NMD pathway. ${ }^{25,31}$ 


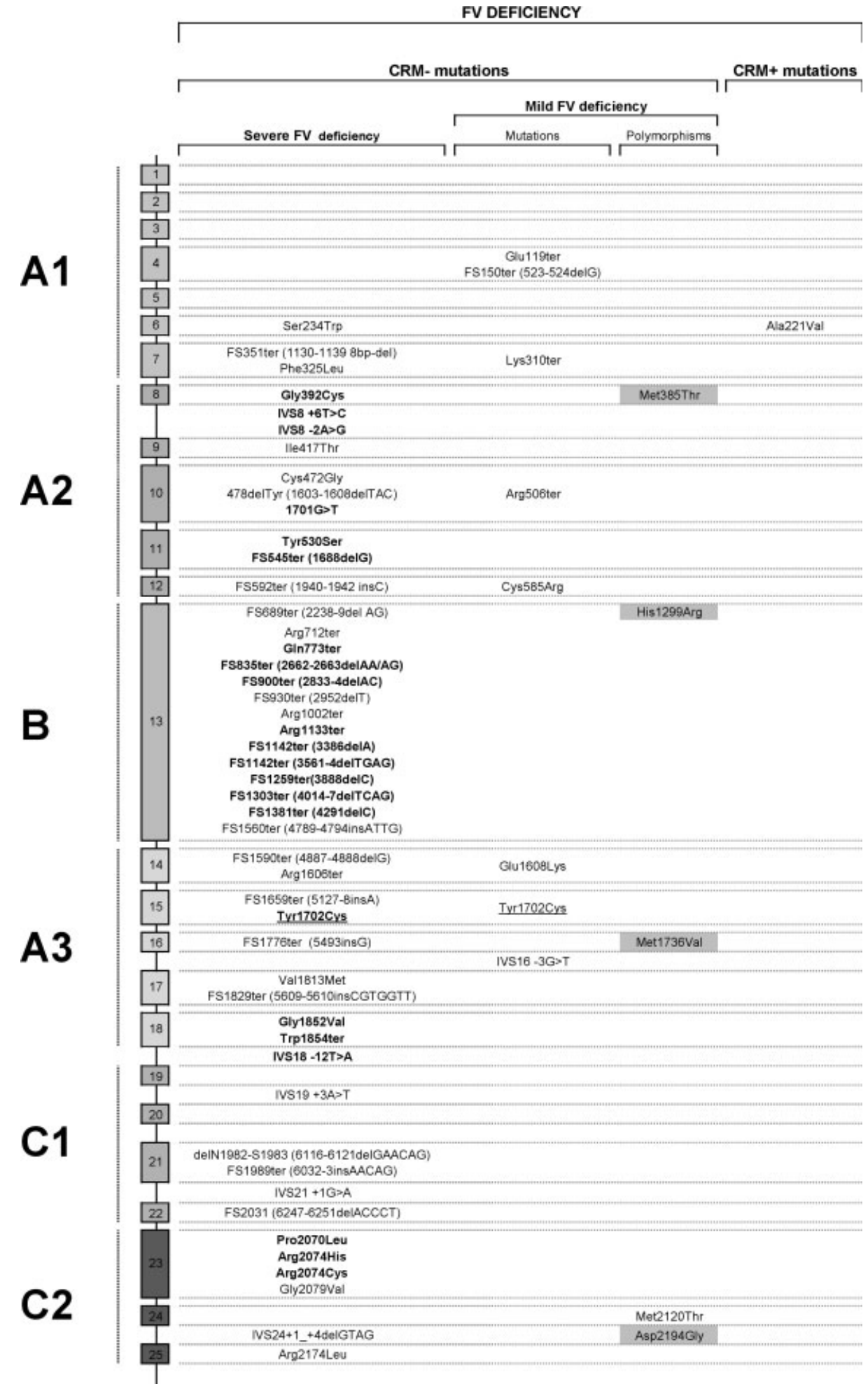

Figure 1 Mutational spectrum of severe and mild FV deficiency. All known causative mutations for type I (CRM-) and type II $(\mathrm{CRM}+) \mathrm{FV}$ deficiency are presented according to their position within F5. Exons and introns are represented by boxes and lines, respectively, and are not drawn to scale. The FV domain structure is also indicated. Mutations are named on the basis of their predicted effect at the protein level (numbering omitting the signal peptide), except for splicing mutations, which are reported according to their nucleotide position (numbering according to the cDNA sequence of F5, GenBank accession no. M16967). As for frameshift mutations, the corresponding nucleotide variation is shown in parentheses. Only full-published mutations are listed. Mutations causing severe FV deficiency found in at least one patient in the homozygous state are set in boldface. The only mutation found both in severe and in mild FV-deficient patients (Tyr1702Cys) is underlined. Mutations belonging to the HR2 haplotype are highlighted in gray. 


\section{MOLECULAR DIAGNOSIS}

Knowledge of the existence of founder effects for specific mutations can be useful to lower the costs and speed up the procedures for the molecular diagnosis of the disease and for its prevention by prenatal diagnosis. This is especially true for those countries where the disorder is highly prevalent (high level of inbreeding) and the resources (facilities and budget) are not abundant. With respect to FV deficiency, genotyping is complicated by the overall paucity of recurrent mutations (except for Tyr1702Cys among Italians), which makes it necessary to sequence the whole coding region of the gene as well as its boundaries in each family. To speed up the procedures for the molecular diagnosis, a straightforward approach could be to first screen exons showing the higher density of reported mutations. In particular, the large exon 13, which is apparently enriched in mutations but also shows a "mutation density" quite lower than the rest of the gene, and whose sequencing is made difficult by the presence of repeated regions, should be initially left aside. Moreover, to save resources and time, the adoption of a DNA-pooling strategy applied to direct sequencing should be taken into account. ${ }^{46}$

The use of a prescreening technique, such as single-strand conformation polymorphism (SSCP), high-performance liquid chromatography (DHPLC), or high-resolution melting (HRM), can also be considered, even though these approaches are hindered by the particular structure of the $F 5$ gene, whose coding region is half contained in a unique exon (exon 13, 2820-bp long), is enriched in repeats, and shows a high number of single nucleotide polymorphisms.

\section{Genotype/Phenotype Correlations}

From mining of the literature, no clear genotype/phenotype correlations clearly emerge between the clinical expression of FV deficiency, plasma FV levels, and the corresponding associated mutations. In fact, patients often present a more severe bleeding phenotype than do others, although they carry the same mutation or show similar FV levels. A possible explanation for these discrepancies could be the different genetic background of patients: for instance, the co-inheritance of FVdeficiency alleles with risk factors for thrombophilia and/or with alleles of modifier genes can influence the overall coagulation cascade, hence affecting the phenotypic expression of the disease. Interestingly, the possibility that severe FV-deficient phenotype may be modulated by a concomitant procoagulant defect was recently investigated by Duckers and colleagues. ${ }^{47}$ They showed that congenital FV deficiency is associated with reduced plasma levels of tissue factor pathway inhibitor (TFPI), which decreases the FV requirement for minimal thrombin generation in FV-deficient plasma to less than $1 \%$, thus probably protecting $\mathrm{FV}$-deficient patients from severe life-threatening bleeding. ${ }^{47}$

\section{PROBLEMS WITH LABORATORY EVALUATION}

\section{Phenotype Analysis}

Because the phenotype evaluation of FV deficiency is initially based on PT and APTT assays, which are both variably prolonged in these patients, it is recommended to follow the published guidelines stating how to handle and process plasma samples. ${ }^{48}$ More recently, Zürcher et al. ${ }^{49}$ investigated the stability of coagulation assays in citrated whole blood transported at ambient temperature, as the stated time limit of 4 hours for nonheparin APTT poses significant constraints to testing in centralized coagulation laboratories. They concluded that clinically significant changes were observed for FV coagulant activity (FV:C) and FVIII coagulant activity (FVIII:C) starting only at 24 to 28 hours, distinct from all other coagulant factors that were found to be more stable.

\section{Genotype Analysis}

In our personal experience on 45 screened patients with severe or mild FV deficiency, in up to $20 \%$ of cases the molecular diagnosis was lacking or incomplete, even after an extensive mutational screening of the gene. Multiple possible explanations can be proposed: (a) PCR-based mutational screenings can miss large heterozygous deletions or large-scale chromosomal rearrangements; (b) deep-intronic mutations are overlooked by conventional coding-region-focused methods; (c) underestimation of the pathogenic role of sequence variants (e.g., synonymous substitutions in the coding sequence interfering with splicing).

Hopefully, the decrease of sequencing costs and the possibility to automate the entire screening workflow will allow a faster and more thorough genetic diagnosis in the near future.

\section{PRENATAL DIAGNOSIS}

In developing countries, where management is still largely inadequate, patients with rare bleeding disorders (RBDs) rarely live beyond childhood. Thus, molecular characterization, carrier detection, and prenatal diagnosis remain the key steps for preventing the birth of children affected by coagulation disorders or for the preparation of on-demand treatment in case of neonatal hemorrhages. For FV deficiency, although life-threatening episodes at birth are rare, the use of prenatal diagnosis can be advisable only in those families with severe clinical history, previously presenting 
affected members. The choice of the strategy (direct or indirect), as well as the choice of the sample to test (e.g., amniocytes or chorionic villi) depends on the effective available budget and facilities to achieve the largest benefit.

\section{THE BEST SCHEME OF TREATMENT}

The choice of dosages and modalities of treatment of bleeding episodes is based on the type of bleeding, on FV levels, and on FV plasma half-life (36 hours). Replacement therapy with FV can be administered only through fresh-frozen plasma (FFP), preferably virus-inactivated, because $\mathrm{FV}$ concentrates are unavailable and $\mathrm{FV}$ is not present in cryoprecipitate or prothrombin complex concentrates. ${ }^{50} \mathrm{FV}$ levels should be raised to at least $15 \mathrm{IU} / \mathrm{dL}^{51}$ by using 15 to $20 \mathrm{~mL} / \mathrm{kg}$ FFP. ${ }^{52}$ The initial dose should be 15 to $20 \mathrm{~mL} / \mathrm{kg}$ followed by smaller amounts, such as $5 \mathrm{~mL} / \mathrm{kg}$ every 12 hours, adjusting the dosage on the basis of FV levels, PT, and APTT. Studies of FV recovery recommend maintaining a level of 20 to $25 \%$ of $\mathrm{FV}$ activity for surgery or in case of severe bleeding. ${ }^{51}$ Surgical procedures should be addressed by administering FFP once a day to achieve minimum levels of $\mathrm{FV}$ of $25 \mathrm{IU} / \mathrm{dL}$ until wound healing is established. ${ }^{51}$

It has been suggested that in cases of severe bleeding not controlled with FFP replacement or in case of inhibitor development, platelet transfusions may be considered. A case of severe FV deficiency associated with multiple episodes of intracranial bleeding at birth was reported, where the inhibitor development due to FFP infusion was solved by additional administration of platelets. ${ }^{53}$ Platelets provide a concentrated supply of FV ( $\sim 20 \%$ of total circulating FV). Therefore, after $\alpha$-granule release upon platelet activation, FV can presumably bind immediately to surface receptors optimizing prothrombinase complex activity. ${ }^{51}$

\section{Complications of Treatment}

Development of alloantibodies to FV in FFP is a potential complication of hereditary $\mathrm{FV}$ deficiency. ${ }^{51}$ After FFP replacement therapy, the occurrence of inhibitors, especially transient ones of low level, may be common $^{51}$ and can be neutralized using large amounts of FFP. ${ }^{50}$ However, as in the treatment of surgical cases, there are concerns over fluid overload in this situation, and close cardiovascular monitoring is hence advisable. Intravenous immunoglobulin may also be effective in eradicating the FV inhibitor. ${ }^{54}$ Platelet infusions have been reported to be effective in acquired FV deficiency, ${ }^{55}$ but it was reported to be effective in stabilizing a subdural hematoma also in a patient with hereditary FV deficiency complicated by inhibitors. ${ }^{56}$ Use of recombinant activated factor VII ( $\mathrm{rFVII}$ ) concentrate was reported at a dosage varying between 80 to $100 \mu \mathrm{g} / \mathrm{kg}$ administrated intravenously, however the hemostatic efficacy in these patients was variable. ${ }^{57-59}$

\section{Treatment in Women: Pregnancy, Delivery, and Menorrhagia}

Menorrhagia is a common bleeding symptom in women with severe FV deficiency. Management of this symptom includes medical treatment such as antifibrinolytics (epsilon-aminocaproic acid at 50 to $60 \mathrm{mg} / \mathrm{kg}$ every 4 to 6 hours; tranexamic acid at $15 \mathrm{mg} / \mathrm{kg}, 1 \mathrm{~g}$ every 6 to 8 hours, orally or intravenously), oral contraceptives, levonorgestrel intrauterine device and replacement therapy, and surgical treatments such as endometrial ablation and hysterectomy. ${ }^{60}$ However, management of women with FV deficiency requires close monitoring of FV levels to ensure that the minimum hemostatic level of $15 \mathrm{IU} / \mathrm{dL}$ has been achieved and awareness of the increased risk of bleeding with any surgical interventions. ${ }^{60}$ There are no published data on management of pregnancy in women with $\mathrm{FV}$ deficiency. ${ }^{51} \mathrm{FV}$ levels in pregnancy do not consistently increase or decrease, hence FV levels should be maintained above the hemostatic level of $15 \mathrm{IU} / \mathrm{dL}$ during labor, using preferably virusinactivated FFP as the source of the factor. If a cesarean section is performed, it would be prudent to continue FV replacement to maintain $\mathrm{PT}$ and $\mathrm{APTT}$ in the normal range until wound healing is complete in women with FV levels of $<15 \mathrm{IU} / \mathrm{dL} .^{51}$

\section{ACKNOWLEDGMENTS}

The authors wish to thank Dr. Elvezia Paraboschi for preparing the mutational spectrum shown in Fig. 1.

\section{REFERENCES}

1. Mann KG, Kalafatis M. Factor V: a combination of Dr Jekyll and Mr Hyde. Blood 2003;101:20-30

2. Stormorken $\mathrm{H}$. The discovery of factor $\mathrm{V}$ : a tricky clotting factor. J Thromb Haemost 2003;1:206-213

3. Mannucci PM, Duga S, Peyvandi F. Recessively inherited coagulation disorders. Blood 2004;104:1243-1252

4. Lak M, Sharifian R, Peyvandi F, Mannucci PM. Symptoms of inherited factor $\mathrm{V}$ deficiency in 35 Iranian patients. Br J Haematol 1998;103:1067-1069

5. Acharya SS, Coughlin A, Dimichele DM; North American Rare Bleeding Disorder Study Group. Rare Bleeding Disorder Registry: deficiencies of factors II, V, VII, X, XIII, fibrinogen and dysfibrinogenemias. J Thromb Haemost 2004; 2:248-256

6. Zhang B, Spreafico M, Zheng C, et al. Genotype-phenotype correlation in combined deficiency of factor $\mathrm{V}$ and factor VIII. Blood 2008;111:5592-5600

7. Kent WJ, Sugnet CW, Furey TS, et al. The human genome browser at UCSC. Genome Res 2002;12:996-1006 
8. Chiu HC, Schick PK, Colman RW. Biosynthesis of factor V in isolated guinea pig megakaryocytes. J Clin Invest 1985;75: 339-346

9. Gewirtz AM, Keefer M, Doshi K, Annamalai AE, Chiu HC, Colman RW. Biology of human megakaryocyte factor V. Blood 1986;67:1639-1648

10. Giampaolo A, Vulcano F, Macioce G, et al. Factor-V expression in platelets from human megakaryocytic culture. Br J Haematol 2005;128:108-111

11. Sun H, Yang TL, Yang A, Wang X, Ginsburg D. The murine platelet and plasma factor $\mathrm{V}$ pools are biosynthetically distinct and sufficient for minimal hemostasis. Blood 2003; 102:2856-2861

12. Dall'Osso C, Guella I, Duga S, et al. Molecular characterization of three novel splicing mutations causing factor $\mathrm{V}$ deficiency and analysis of the F5 gene splicing pattern. Haematologica 2008;93:1505-1513

13. Frischmeyer PA, Dietz HC. Nonsense-mediated mRNA decay in health and disease. Hum Mol Genet 1999;8:18931900

14. Lejeune F, Maquat LE. Mechanistic links between nonsense-mediated mRNA decay and pre-mRNA splicing in mammalian cells. Curr Opin Cell Biol 2005;17:309-315

15. Jenny RJ, Pittman DD, Toole JJ, et al. Complete cDNA and derived amino acid sequence of human factor V. Proc Natl Acad Sci U S A 1987;84:4846-4850

16. Cripe LD, Moore KD, Kane WH. Structure of the gene for human coagulation factor V. Biochemistry 1992;31:37773785

17. Nicolaes GA, Dahlbäck B. Factor V and thrombotic disease: description of a janus-faced protein. Arterioscler Thromb Vasc Biol 2002;22:530-538

18. Xue J, Kalafatis M, Mann KG. Determination of the disulfide bridges in factor Va light chain. Biochemistry 1993; 32:5917-5923

19. Xue J, Kalafatis M, Silveira JR, Kung C, Mann KG. Determination of the disulfide bridges in factor $\mathrm{Va}$ heavy chain. Biochemistry 1994;33:13109-13116

20. Kumar HPM, Besman MJ, Lundblad RL, Jenny NS, Mann KG. Carbohydrate analysis of plasma factor $\mathrm{V}$ and factor VIII. Thromb Haemost 1999;(Suppl 82):102a

21. Macedo-Ribeiro S, Bode W, Huber R, et al. Crystal structures of the membrane-binding $\mathrm{C} 2$ domain of human coagulation factor V. Nature 1999;402:434-439

22. Adams TE, Hockin MF, Mann KG, Everse SJ. The crystal structure of activated protein $\mathrm{C}$-inactivated bovine factor $\mathrm{Va}$ : implications for cofactor function. Proc Natl Acad Sci U S A 2004;101:8918-8923

23. Stoilova-McPhie S, Parmenter CD, Segers K, Villoutreix BO, Nicolaes GA. Defining the structure of membranebound human blood coagulation factor Va. J Thromb Haemost 2008;6:76-82

24. Lee CJ, Lin P, Chandrasekaran V, et al. Proposed structural models of human factor $\mathrm{Va}$ and prothrombinase. $\mathrm{J}$ Thromb Haemost 2008;6:83-89

25. Asselta R, Tenchini ML, Duga S. Inherited defects of coagulation factor $\mathrm{V}$ : the hemorrhagic side. J Thromb Haemost 2006;4:26-34

26. Lunghi B, Scanavini D, Castoldi $\mathrm{E}$, et al. The factor $\mathrm{V}$ Glu1608Lys mutation is recurrent in familial thrombophilia. J Thromb Haemost 2005;3:2032-2038

27. Schrijver I, Hong DW, Mandle L, et al. High frequency of premature termination mutations in the factor $\mathrm{V}$ gene: three factor $\mathrm{V}$ deficiency case reports and a mutation review. Thromb Haemost 2005;93:610-611

28. Asselta R, Dall'Osso C, Duga S, Spreafico M, Saxena R, Tenchini ML. Coagulation factor $\mathrm{V}$ gene analysis in five Indian patients: identification of three novel small deletions. Haematologica 2006;91:1724-1726

29. Kling SJ, Griffee M, Flanders MM, Rodgers GM. Factor V deficiency caused by a novel missense mutation, Ile417Thr, in the A2 domain. J Thromb Haemost 2006;4:481-483

30. Traynis I, Jones CD, Gibb CB, Acharya SS, Zehnder JL. First molecular characterization of a patient with combined factor V and factor VII deficiency. Thromb Haemost 2006; 95:1031-1032

31. Yamakage N, Ikejiri M, Okumura $K$, et al. A case of coagulation factor $\mathrm{V}$ deficiency caused by compound heterozygous mutations in the factor $\mathrm{V}$ gene. Haemophilia 2006;12: 172-178

32. Zheng WD, Liu YH, Liu HF, Chen ZH, Wang Y. [Identification of two novel mutations of human blood coagulation factor $\mathrm{V}$ gene in a Chinese family with congenital factor V deficiency]. Zhonghua Yi Xue Yi Chuan Xue Za Zhi 2006;23:515-518

33. Cai XH, Wang XF, Ding QL, Fu QH, Wang HL. Factor V C1149G and 5609-10INSCGTGGTT causing factor V deficiency: molecular characterization by in-vitro expression. Thromb Haemost 2007;98:683-685

34. Caudill JS, Sood R, Zehnder JL, Pruthi RK, Steensma DP. Severe coagulation factor $\mathrm{V}$ deficiency associated with an interstitial deletion of chromosome 1q. J Thromb Haemost 2007;5:626-628

35. Jones CD, Yeung C, Negro F, Zehnder JL. Molecular characterization and subcellular localization of Tyr478del: a pathogenic in-frame deletion in coagulation factor $\mathrm{V}$. J Thromb Haemost 2007;5:431-433

36. Shinozawa K, Amano K, Suzuki T, et al. Molecular characterization of 3 factor $\mathrm{V}$ mutations, R2174L, $\mathrm{V} 1813 \mathrm{M}$, and a 5-bp deletion, that cause factor $\mathrm{V}$ deficiency. Int J Hematol 2007;86:407-413

37. Lunghi B, Pinotti M, Maestri I, Batorova A, Bernardi F. Evaluation of factor $\mathrm{V}$ mRNA to define the residual factor $\mathrm{V}$ expression levels in severe factor $\mathrm{V}$ deficiency. Haematologica 2008;93:477-478

38. Song J, Guella I, Kwon KY, et al. A novel in-frame deletion in the factor $\mathrm{V} \mathrm{C} 1$ domain associated with severe coagulation factor $\mathrm{V}$ deficiency in a Korean family. Blood Coagul Fibrinolysis 2009;20:150-156

39. Vos HL. An online database of mutations and polymorphisms in and around the coagulation factor $\mathrm{V}$ gene. J Thromb Haemost 2007;5:185-188

40. Castoldi E, Lunghi B, Mingozzi F, et al. A missense mutation $(\mathrm{Y} 1702 \mathrm{C})$ in the coagulation factor $\mathrm{V}$ gene is a frequent cause of factor $\mathrm{V}$ deficiency in the Italian population. Haematologica 2001;86:629-633

41. Scanavini D, Girelli D, Lunghi B, et al. Modulation of factor $\mathrm{V}$ levels in plasma by polymorphisms in the $\mathrm{C} 2$ domain. Arterioscler Thromb Vasc Biol 2004;24:200-206

42. Vos HL. Inherited defects of coagulation factor V: the thrombotic side. J Thromb Haemost 2006;4:35-40

43. Yamazaki T, Nicolaes GA, Sørensen KW, Dahlbäck B. Molecular basis of quantitative factor $\mathrm{V}$ deficiency associated with factor V R2 haplotype. Blood 2002;100:2515-2521

44. Murray JM, Rand MD, Egan JO, Murphy S, Kim HC, Mann KG. Factor V New Brunswick: Ala221-to-Val 
substitution results in reduced cofactor activity. Blood 1995; 86:1820-1827

45. Steen M, Miteva M, Villoutreix BO, Yamazaki T, Dahlbäck B, Factor V. Factor V New Brunswick: Ala221Val associated with FV deficiency reproduced in vitro and functionally characterized. Blood 2003;102:1316-1322

46. Monaldini L, Asselta R, Malcovati M, Tenchini ML, Duga $\mathrm{S}$. The DNA-pooling technique allowed for the identification of three novel mutations responsible for afibrinogenemia. J Thromb Haemost 2005;3:2591-2593

47. Duckers C, Simioni P, Spiezia L, et al. Low plasma levels of tissue factor pathway inhibitor in patients with congenital factor V deficiency. Blood 2008;112:3615-3623

48. Adcock DM, Hoefner DM, Kottke-Marchant K, Marlar RA, Szamosi DI, Warunek DJ. Collection, Transport, and Processing of Blood Specimens for Testing Plasma-Based Coagulation Assays and Molecular Hemostasis Assays: Approved Guideline, Fifth Edition. Wayne, PA: Clinical Laboratory Standards Institute; 2008; CLSI document H21-A5

49. Zürcher M, Sulzer I, Barizzi G, Lämmle B, Alberio L. Stability of coagulation assays performed in plasma from citrated whole blood transported at ambient temperature. Thromb Haemost 2008;99:416-426

50. Di Paola J, Nugent D, Young G. Current therapy for rare factor deficiencies. Haemophilia 2001;7(Suppl 1):16-22

51. Bolton-Maggs PH, Perry DJ, Chalmers EA, et al. The rare coagulation disorders-review with guidelines for management from the United Kingdom Haemophilia Centre Doctors' Organisation. Haemophilia 2004;10:593-628

52. Peyvandi F, Duga S, Akhavan S, Mannucci PM. Rare coagulation deficiencies. Haemophilia 2002;8:308-321
53. Salooja N, Martin P, Khair K, Liesner R, Hann I. Severe factor $\mathrm{V}$ deficiency and neonatal intracranial haemorrhage: a case report. Haemophilia 2000;6:44-46

54. Tarantino MD, Ross MP, Daniels TM, Nichols WL. Modulation of an acquired coagulation factor $\mathrm{V}$ inhibitor with intravenous immune globulin. J Pediatr Hematol Oncol 1997;19:226-231

55. Chediak J, Ashenhurst JB, Garlick I, Desser RK. Successful management of bleeding in a patient with factor $\mathrm{V}$ inhibitor by platelet transfusions. Blood 1980;56:835-841

56. Salooja N, Martin P, Khair K, Liesner R, Hann I. Severe factor $\mathrm{V}$ deficiency and neonatal intracranial haemorrhage: a case report. Haemophilia 2000;6:44-46

57. Altisent C, Lozano M, Sol E, et al. Dental extraction using rFVIIa in a patient with severe FV deficiency. Haemophilia 2000;6:408

58. Divanon F, Hecquard C, Borel-Derlon A. Experience with use of recombinant activated factor VII. J Clin Pharm Ther 2002;27:133-138

59. González-Boullosa R, Ocampo-Martínez R, Alarcón-Martín MJ, Suárez-Rodríguez M, Domínguez-Viguera L, GonzálezFajo G. The use of activated recombinant coagulation factor VII during haemarthroses and synovectomy in a patient with congenital severe factor V deficiency. Haemophilia 2005;11: $167-170$

60. Lee CA, Chi C, Pavord SR, et al; UK Haemophilia Centre Doctors' Organization. The obstetric and gynaecological management of women with inherited bleeding disordersreview with guidelines produced by a taskforce of UK Haemophilia Centre Doctors' Organization. Haemophilia 2006;12:301-336 